\section{Need for the appraisal of uncommon side effects of a commonly prescribed drug- Imatinib}

Dear Sir,

The concept of targeted therapy is emerging as an innovative, high potential new trend in cancer therapy. These drugs are not supposed to affect the normal cells and act selectively on cancer cells there by minimizing the systemic side-effects. H owever the results are not as expected. O ne of such novel drugs (first of its kind to be approved by FDA) is I matinib, a Bcr-A bl tyrosine kinase inhibitor. It has been used in patients of chronic myeloid leukemia and Gastro Intestinal Stromal Tumor (GIST) and has been under evaluation for many more indications. It is usually well tolerated, with relatively minor toxicities like fluid retention and skin changes. However, with the time, oncologists are noticing newer side effects which were not reported in the initial phases of drug trials. The more recently reported ones are, O totoxicity, ${ }^{[1]}$ cardio toxicity ${ }^{[2]}$ and optic neuritis. ${ }^{[3]}$ It is probably due to the mitochondrial dysfunction as hypothesized by Grazette et al, in their in vitro studies. ${ }^{[4]}$ This entity requires further attention as majority of the patients receiving therapy are relatively young, the therapy often leads to long disease-free survival and the toxicity [mitochondrial damage leading to cardio toxicity and neurotoxicity] results in considerable morbidity.

Attili VSS ${ }^{1}$, Anuradha V', Raju SHK ${ }^{3}$ Department of Medical Oncology, Yashoda Hospitals, Hyderabad, 'Department of Pathology, Osmania Medical College, Hyderabad, ${ }^{2}$ Department of Medicine, IMS, BHU, Varanasi, UP, India

Correspondence to: Dr AVS Suresh, E-mail: sureshattili@yahoo.com

\section{References}

1. AttiliVS, Bapsy PP, Anupama G, Lokanatha D. Irreversible sensorineural hearing loss due to Imatinib. Leuk Res 2008;32:991-2.

2. Kerkela R, Grazette L, Yacobi R, lliescu C, Patten R, Beahm C, et al. Cardiotoxicity of the cancer therapeutic agent Imatinib mesylate. Nat Med 2006; 12:908-16.

3. Govind Babu K, Attili VS, Bapsy PP Anupama G. Imatinib-induced optic neuritis in a patient of chronic myeloid leukemia. Int Ophthalmol 2007;27:43-4.

4. Grazette LP, Kerkela R, Patten R. Imatinib mesylate (Gleevec) induces mitochondrial dysfunction and caspase activation in cardiac myocytes. J Card Fail 2005;11:S 126. 